\title{
New data affects forestry-related impacts of global warming theories
}

\author{
David South
}

\section{Correspondence}

Dear Editor

I am writing to draw your readers' attention to recently published findings that, in my opinion, will alter the way we think about "greenhouse gasses/global warming." These findings may cause critical thinkers to question the effectiveness of "carbon-sequestration plantations" (aimed at altering atmospheric temperatures).

Traditionally, the effect of having an atmosphere has been estimated to increase the Earth's average temperature by $33{ }^{\circ} \mathrm{C}$. However, Volokin and ReLlez (2014) provided mathematical and empirical evidence that the effect of nearly 1-bar atmosphere on Earth's average temperature is around $90{ }^{\circ} \mathrm{C}$. ${ }^{1}$ The authors showed that the $33{ }^{\circ} \mathrm{C}$ estimate referred to in virtually all meteorology/climate textbooks for the past 40 years has been a result of incorrect application of the Stefan-Boltzmann radiation law to a sphere. The study also demonstrates for the first time that the atmospheric thermal effect has a significant non-radiative component controlled by air pressure. Based on these findings, the contribution of greenhouse gasses to Earth's fluctuating temperature will remain uncertain until the magnitude of the newly identified thermodynamic temperature enhancement is fully quantified by future research.

In a subsequent paper, Volokin and ReLlez (2015) developed a new macro-level model using data from six celestial bodies in our solar system (i.e., Venus, Moon, Earth, Mars, Titan, and Triton). Amazingly, their model accurately predicts the mean global temperatures of rocky planets (with diverse atmospheres) using only two variables: top-of-the-atmosphere solar irradiance and total surface atmospheric pressure. According to the authors, "The new model displays characteristics of an emergent macro-level thermodynamic relationship heretofore unbeknown to science that deserves further investigation and possibly a theoretical interpretation." The model fully explains the previously mentioned $\sim 90{ }^{\circ} \mathrm{C}$ atmospheric effect as a function of atmospheric pressure and solar irradiance. The authors show that neither the concentration nor the partial pressure of greenhouse gasses can satisfactorily predict the observed variation of global planetary temperatures across the solar system.

These new results indicate that the pressure of Earth's atmosphere plays a key role in keeping the planet warm while accounting for virtually $100 \%$ of the so-called natural greenhouse effect. This implies that the rising levels of "greenhouse gasses" may have little to no effect on future climate. The findings by Volokin and ReLlez (2014, 2015) may improve our understanding of the possible impact of afforestation on global temperature as follows:

Some researchers say that a massive afforestation effort might warm the Earth by $0.1{ }^{\circ} \mathrm{C}$ (Davies-Barnard et al. 2014) while many foresters assume that removing $8.7 \mathrm{Gt}$ of carbon from the atmosphere (by planting trees) would delay anthropogenic global warming by about one year. $^{2}$ Although arriving at contradictory conclusions, both of these groups have assumed that carbon dioxide and other trace gasses, rather than atmospheric pressure, have warmed the Earth by about $33{ }^{\circ} \mathrm{C}$. However, the findings of Volokin and ReLlez $(2014,2015)$ cause us to question: (1) the theoretical foundation of the "greenhouse" theory itself; and (2) the belief that large-scale carbon sequestration can alter the global mean temperature. Readers should be aware that atmospheric science is not set in stone; there is plenty of room for the evolution of our understanding on this complex topic.

The above scientific breakthrough is not to say that we as foresters do not have a stewardship responsibility for protecting forests and establishing tree plantations. However, our reason for tree planting should no longer rest on the belief that greenhouse gas emissions will cause catastrophic global warming.

David South is Emeritus Professor, Auburn University. 


\section{Endnotes}

${ }^{1}$ The value of $33{ }^{\circ} \mathrm{C}$ was obtained from the difference between the current average temperature of the Earth including its atmosphere $\left(\approx 15^{\circ} \mathrm{C}\right)$ and a calculated value of $-18{ }^{\circ} \mathrm{C}$ for the Earth's mean temperature without an atmosphere. However, Volokin and ReLlez (2014) showed that a more correct estimate for the Earth's mean temperature without an atmosphere is about $-75^{\circ} \mathrm{C}$. This error has been caused by incorrect application of the Stefan-Boltzmann radiation law to spheres. Taking $15^{\circ} \mathrm{C}$ and subtracting $-75^{\circ} \mathrm{C}$ results in a value of $90^{\circ} \mathrm{C}$.

${ }^{2}$ The total emissions of carbon to the atmosphere caused by fossil fuel combustion for the year 2008 are widely reported as 8.7 Gt, e.g., Geri and Mc Nabb (2011).

\section{Competing interests}

The author declares that he has no competing interests.

Received: 7 July 2015 Accepted: 15 October 2015

Published online: 11 November 2015

\section{References}

Davies-Barnard, T, Valdes, PJ, Singarayer, JS, Pacifico, FM, Jones, CD. (2014). Full effects of land use change in the representative concentration pathways. Environmental Research Letters, 9:114014.

Geri, LR, \& McNabb, DE. (2011). Energy policy in the US: politics, challenges and prospects for change. CRC Press: Boca Raton, FL, USA.

Volokin, D, \& ReLlez, L. (2014). On the average temperature of airless spherical bodies and the magnitude of Earth's atmospheric thermal effect. SpringerPlus, 3:723. doi:10.1186/2193-1801-3-723.

Volokin, D, \& ReLlez, L. (2015). Emergent model for predicting the average surface temperature of rocky planets with diverse atmospheres. Advances in Space Research. doi:10.1016/j.asr.2015.08.006.

\section{Submit your manuscript to a SpringerOpen ${ }^{\circ}$} journal and benefit from:

- Convenient online submission

- Rigorous peer review

- Immediate publication on acceptance

- Open access: articles freely available online

- High visibility within the field

- Retaining the copyright to your article 